\title{
Commemorating Charles Tilly
}

\author{
Lawrence T. Nichols
}

Published online: 8 December 2010

(C) Springer Science+Business Media, LLC 2010

In his Visions of the Sociological Tradition, Don Levine reminded us that the invention of sociology required exceptional acumen and powerful intellects. In this issue we present a set of papers in honor of a highly respected and widely influential scholar who is best known for his efforts to combine work in sociology and in history, which remains a relatively unusual combination. Sociology's origins as a distinct field of study in American universities are often traced to economics, and sometimes also to moral philosophy and socio-political activism. Less attention is generally accorded to history, although some European influences on U.S. sociology were clearly historical in nature - perhaps most notably the writings of Max Weber on comparative institutions. We may hope that the model Tilly provided will inspire future efforts in the same genre.

I had the privilege of meeting Charles Tilly only once, several years ago, at a didactic seminar on the history of sociology that was organized by Ed Tiryakian. I found him immediately likeable and approachable, and his enthusiasm for sociology was palpable. He also seemed to relish his memories of colleagues and teachers such as Pitirim A. Sorokin at Harvard. It would, I believe, be a great blessing for our field if all of us could find similar joy in our work.

Special thanks are due to Andreas Koller, who shared in the editorial work of producing this issue. Andreas served as organizer, acted as liaison with all authors, read all submissions and helped authors polish and strengthen their work. I have greatly enjoyed collaborating with him, and I feel confident that readers will also appreciate the fruits of his patient labors.

L. T. Nichols $(\bowtie)$

Division of Sociology and Anthropology, West Virginia University, Morgantown, WV, USA

e-mail: Larry.Nichols@mail.wvu.edu 